\title{
Surface Warship Deduction Laboratory Teaching Mode Research Based on the Information System
}

\author{
Liang Ma \\ Department of Surface Ship Command, Dalian Naval Academy, Dalian, 116018, China \\ 446982051@qq.com
}

Keywords: Information system; Surface warship deduction laboratory; Inference implementation

\begin{abstract}
The surface ship combat history shows that science and technology has not only promoted the change of operational mode, but also promoted the people understand and study how to implement the development of operational experiments. With the rapid development of modern science and technology, especially information technology, for the study of the surface warship deduction experiment provides methods and platforms. By relying on simulation system, command and experiment personnel can be implemented in the laboratory practice methods and inspection operations philosophy, thus promotes surface ships tactics theory, operational analysis and training level of overall jumped. In this paper, the surface ship battle LABS deduction how to implement are studied, provide methods for the construction of surface ship battle LABS support and technical reference.
\end{abstract}

\section{Introduction}

Surface warship deduction lab is based on military science, operational research, systems engineering and modern warfare simulation technology, on the basis of the ability to create realistic models of virtual naval battle field, sea power and command post, for students study to explore the law of naval warfare and method of evaluation of various kinds of operational decisions, weapon use and operational scheme provides research, experiment and training platform, through to the students of different schemes for the decision-making and deduction analysis, improve the level of students' military planning and decision, for students to adapt to the future job positions offer perceptual knowledge and experience practice platform, again through the deductive process of accumulating experience, improve command decision-making, control, coordination of the operation ability of ships and vessels formation on the sea, by participating in different combat scenario against deduction, improve the ability of vessel command and tactical use, quality and level.

\section{Surface Warship Deduction Laboratory Construction Requirements Based on the Information System}

Based on the laboratory construction demands of information system, should be geared to the needs of combat troops based on information system in the new period and training requirements. As alignment has gradually become the system operational capability of core to stand, and achieve operational system based on fusion has become the promotion of comprehensive information system of important gripper system operational capability.

(1) To realize the integration of information systems

Information system is not only the important constitute part of the combat system, and it is the organic connection of public information platform, combat system and effective operation of the combat system plays a foundation to support role. Implement the information system integration, is the core of the system operational capability construction engineering. Must in order to promote the standardized construction as the gripper, attach importance to the overall design of information technology, through the methods of internal integration and external penetration, weapons platform, operational factors, such as combat system integrating information systems, and make all of the information system has a unified data standards and standard data interface, and realize the $d$ 
battlefield information synchronization of interconnectivity sharing, realize the intensive and efficient operation of the combat system.

(2) Achieve the fusion of the combat system

Any combat system is made up of the corresponding intelligence reconnaissance system, command and control system, firefighting system, the whole protection system and integrated security system and other subsystem integration. Realize the fusion of the combat system, is the basic content of the system operational capability construction. Must be scientific configuration and optimization combination of combat system, build up the operational system of the chain structure of science, with scientific structure data link chain codes, to support data link information chain, make each combat system can close together, together, interconnection and interaction, the overall control, give full play to the efficiency of the combat system, to achieve the effect of the whole is greater than the sum of the parts.

(3)Realize the combat system

System based on information system, is a joint and combined arms combat. Services and arms for a long time, our construction market fragmentation, sui generis, low operational system alignment and combined arms, poor compatibility. Realize the fusion between and combined arms combat system, which is a key link in the process of system capability. Must straighten out all the services and arms relatively discrete command system and direct relationship, change "chimney" system, break the barrier of the department, a vertical, horizontal integration and seamless interconnection architecture, make operational system and combined arms command interconnection, information exchange and weapons and equipment interoperability, the capacity of integrated joint operations.

(4)To achieve the operational level

Combat system, and based on the information system is a covers strategic, operational and tactical level, has the adaptability of the open complex system. Implementation of operational system, at the level of system is in order to combat capability. Must in view of the open complex giant system, pays special attention to the operational system of the construction of the overall planning and path selection, break the strategic, operational and tactical level operational system are relatively independent, the system of the construction of the hierarchical barriers, enhance operational system of systematic, adaptability and flexibility, implementation of combat system between information accessible at the level of vertical circulation, unification, effective command and control, and timely and effective support.

Based on the information system of laboratory construction, it should be oriented to the requirements of the above four fusion, according to the actual circumstance of force development, completes the simulator and live-fire information fusion, on the experimental teaching idea constantly updated at the same time, advanced research and development.

\section{The Surface Warship Deduction to Organize the Implementation of the Content and Method}

The Surface Warship Deduction to Organize the Implementation of the Content. In line with actual combat, the content of the surface warship deduction to organize the implementation of the is usually the same as the actual combat style, including offensive operations at sea and offshore defensive operations. From both sides fighting forces against, including surface ships to fight against the surface ships, surface warships to fight against the submarines, surface warships to fight against the land, surface ships air defense operations and mine surface ships and mine operations.

Surface Warship Deduction on the Implementation of the Method. Surface warship inference implementation mainly has three ways: the red (personnel) and blue (personnel) packet counter - people in the loop, red (personnel) and blue (computer) against - people in the loop, red (computer) and blue (computer) - out of the loop. On the basis of surface ship combat inference to implement these three ways, can be applied on the deductive method can be divided into: first, according to the operational implementation. According to the preset operational, according to the 
surface ship battle command process to organize the implementation, need to determine the battle in an attempt to, strength classification, organization and command organization major combat operations. Second, according to the operational plan to organize the implementation. Need to verify a scheme is workable or choose the optimal solution from many schemes. This method based on the combat scheme the process and outcome of deduction, to dynamic and intuitive experiment scheme, the commander of the battle plan at present both sides against the deduction of interaction. Third, around to organize the implementation of operational problem. Mainly around the typical combat simulation analysis, simulations need to trial and error, the operational problems and regularity and has reference value of the conclusions and recommendations.

Surface Warship Inference Implementation Process. Surface ship battle LABS of battle command is to let students play the combatant commander and commanding organ staff, reasonable use system using the surface ship force, flexible use of tactics to attain the goal of fighting, and organized leadership, including the battlefield information widely, decisive decision-making and control, make the war the surface ship force, in accordance with the operational intention to maximize the comprehensive combat capability, thus to realize the purpose of the research methods and inspection methods.

Surface warship process is divided into groups and combat command, the process is shown in Fig. 1:

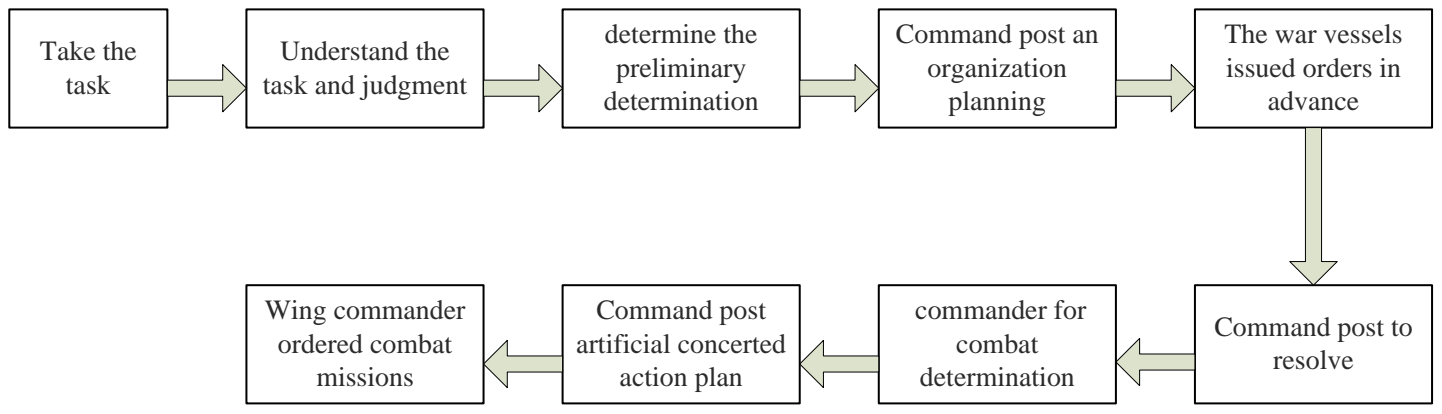

Figure 1. battle plan surface ship formation in the basic flow

\section{The Surface Warship Deduction to Organize the Implementation of the Steps}

Organization and implementation of surface warship combat exercise usually can be divided into three steps: deduction plan preparation stage, summarize the inference organization implementation stage and the deduction of the assessment phase.

Surface Warship Deduction Plan Preparation Stage. Surface warship deduction plan preparation phase usually include: the deduction system preparation, preparation of deduction plan scenarios, deduction personnel organization and timely deduction in advance.

(1) Deduction system

Surface ship operations deduction system, including the choice of operation module (e.g., to attack the module, and the air defense module, mine module, etc.) and determine the operation scheme (such as to determine the ship attack methods), ready to ship data (such as to determine the number of ships carry anti-ship missiles and kill probability) and the system state testing. Surface warships tactical exercise platform consists of several subsystems, according to the operational design which determine the content of the application subsystem and use what kind of operation scheme, at the same time, based on the current naval warfare environment and the existing ship weapon equipment to enrich and update the database (database including weapons and combat environment database), and according to the needs of the surface ship tactical problem research, determine the use of all kinds of models.

(2) to set the plan preparation 
Surface warship inference to decide the solution preparation, including both red and blue against the basic scheme, deduction scenarios, implementation plan and guide adjustment scheme of department director.

Red and blue sides against the basic rules for the purpose of surface warships tactical deduction, the requirements of the focus, the deductive process, content and methods of inference implementation applied on the deduction, and many other problems. Surface warship deduction scenarios are to combat the deduction set basic situation, combat mission and requirement for the specific planning and setting. Deduction scenarios involving both red and blue against global whole process and all aspects of the situation, mainly red blue surface ship formation before the fighting between the two sides situations. Deduction want will usually include the red and blue to decide, is red and blue surface ship and fleet commander confrontation between the two sides basic ideas. Deduction in simulated scenarios and distribution of deduction to be ready before you start to fight against the personnel of sides, deduction, phased implementation team to step guide both sides to the scenario set, exercise leadership team and implementation team must be in accordance with the deduction to guide the direction on the implementation of deduction. Both sides against the deduction of the implementation of the plan, it is according to the content and requirements of surface warship teaching, main research problems in the process of fighting deduction, the deduction process, the duration of deduction, the deduction methods and so on carries on the overall arrangement. Inference implementation plan according to procedure, methodically proceed smoothly. Director of quasi guidance tuning scheme is to fight for effective control of surface ship deduction process, ensure the deduction for the desired purpose, guide adjustment scheme is usually based on the deduction to initial situation and both sides, the drafting in the form of bulletin, instruction, etc.

(3) Inference personnel organization

Implementation of surface warship deduction need to organize the implementation of personnel for inspection, software and hardware system maintenance, etc., to ensure that the operational deduction can be sustained and smoothly. Meanwhile, for surface warships combat inference results also needs to organize deduction personnel is analyzed and evaluated. Participate in combat exercise leadership and implementation personnel usually by the strong organization ability and the theory of surface warship personnel to organize the implementation of knowledge. According to the size of the surface warship deduction, deduction researchers often make up for the director of department, team, red command control group and the blue command and control group.

(4) Deduction in advance

Surface warship deduction is the deduction plan in advance to prepare the final stages of exercise leadership and implementation personnel shall duly deduction in advance to find major problems that exist in the deductive process and implement solutions, so as to ensure smooth implementation of the practical deduction. At the same time, must advance to deduction system hardware and software debugging, inference implementation personnel to check the deduction system hardware is normal, steady running, whether the deduction is applied to the software module function are in conformity with the tactical exercise, etc.

Surface warship deduction to organize the implementation of the stage. Surface warship deduction to organize and implement, usually adopt the way of people in the loop, the people involved in inference. This battle deduction method required in personnel involved, and expands access, decision plan formulation and coordination control command.

(1) Inference implementation process

General process of surface warship deduction is released from the director of operations start time. Both sides according to the scheme of deduction to take their own use of "tactics", the director department according to the proposed plan usually lead to the warring sides respectively 
the plot and briefing, which reflects the situation of the enemy during the exercise to prepare, my feeling, a major change in the naval battle field situation, etc., to ensure the continuity of the inference process. Briefing is usually based on operational implementation of the practical need of and against both commander command decisions of the key points and make the necessary guidance and specification, guarantee the deduction as planned, and lays the foundation for subsequent deduction.

Against both deduction personnel from director department after comprehensive conditions to the sea, shall immediately organize the analysis judgment, decision response, etc. Response can be planned in advance, also can be according to the new situation and to make the occasion requires. Inference implementation personnel responsible for continuously collected in the implement process of deduction against both the situation and maintain communication and contact with director department, according to the intention of the director of actively guide deduction process, lead against the direction of the two sides in accordance with regulations of the operational deduction.

The surface ship commanders in combat deduction in the process of implementation of the command activities including intelligence, judgment, decision-making, ordered four stages, after the warring sides commander to make decisions, to timely operational orders for disposal of encounter situation. Deduction system after executing the command, to form a new naval battle field situation, and create conditions for the next stage both sides fight, so to finish the whole course of combat deduction.

(2) Inference implementation ways

Implementation of surface warship against the deduction, need a series of round, each round represents a deduction stage. For example, red surface ship formation combat action must lead to blue to take corresponding measures, both red and blue form the adversarial relationship, you come to me to push forward the whole inference process. From the perspective of a general inference implementation way, combat deduction can be divided into stages deduction and continuity.

Periodic deduction, it is according to the needs of deduction purpose, in a confrontation in the process of implementation, as to speed up or slow down the process of exercise, for the secondary phase can speed up the process, for key stage can slow down the process, so as to focus on and time to focus on implementation of operational key link in the process of inference. Periodic deduction can usually be intermittent, midway stop watch, in the next stage continue to extrapolate a continuation of a stage.

Coherence deduction, it is uninterrupted, continuous operational implementation process of deduction, until finish the mission, we can accomplish deduction required by the overall goal. Coherent inference is usually not stop watch; sometimes in personnel need continuously to work day and night, until the successful completion of tasks.

Surface Warship Inference Summarizes the Evaluation Period. Surface warship inference summarizes the assessment phase is directed by the department organization against both in personnel systematically analysis the result of the combat deduction, research, evaluation and summary, to comb the understanding of tactical methods, discuss the pros and cons of factors in the process of application of tactics, found problems in the process of the battle command and seeking ways to solve these problems, at the same time can also help researchers in combat experience, explore new tactical application method, application methods in actual work practice for the future lay a solid foundation.

Inference summarizes the evaluation of the main contents include: basic information is a summary, including the surface warship deduction on the implementation of the project, the purpose of the exercise, guiding ideology, the two sides against the process and the result of confrontation, etc.; Second, evaluation of tactical application, including against the two sides adopt the tactics of thinking, the pros and cons of battle command mode, etc.; 3 it is 
improvement and innovation of operational method of use, and what problem need to pay attention to in the process of operational application. Inference summarizes evaluation focuses on against both knowledge of combat missions, to combat situation judgment and decision making when considering the main factors.

Analysis the result of the combat inference implementation summary, the first thing to compile the deductive process, according to the actual performance of deduction, need to focus on the problems in the process of inductive inference, still can use deduction system for previous naval battle field situation and confrontation situation repeated deduction; The second is to organize the collective discussion, after fighting deduction, organization discuss the difficulties encountered in the process of deduction, the deduction focus and confused problems, explore the fight against the two sides to make decisions and organize the implementation of the harvest obtained and made mistakes. At the same time, the surface warship inference summarizes the evaluation results will ultimately form the report. Report to the deduction of the implementation of the methods, implementation, and evaluation results, etc. Make detailed instructions. Surface warship inference summarizes the assessment report mainly includes: combat deduction purpose, date and deduction, deduction operations/points deduction in the laboratory room, operations deduction experimental conditions/equipment, combat deduction experiment contents, operational approach of deduction, combat deductive process records, inference results analysis, evaluation and conclusions, etc.

Finally, the battle against both deduction and evaluate the result of the deduction, needs assessment indicators and rules. Against losses on sea fighting is decision, by the system model can also be combined with the system by the director of personnel considers the factors determine the winning side. For relying on the combat simulation system for the deduction, the deduction is not the main result, do not have to stick to the success or failure of the outcome, the deduction of engagement is the key to the exercise in personnel tactics, familiar with the process of operation command, improve the application and innovation methods of ideology and enhance the ability to command the occasion requires.

\section{Conclusions}

Based on information system of colleges and universities laboratory for teaching at the same time, can become an important part of the system of naval combat, both red and blue through against deduction simulation can take on operational research, testing, training and assessment tasks, such as its construction to meet the requirements of the system based on information system operations.

\section{References}

[1] Galay Barbarosoglu, Linet Ozdamar, Ahmel Cevik. An Interactive Appmach of Hierarchical Analysis of Helicopter Logistics in Disaster Relief Operations[J]. European Journal of Operational Research, 2002: 118-133

[2] Omid Shakernia. Vision-based Control and Coordination of Unmanned Vehicles[D].California: University of California, Berkely 2003

[3] Sriram Venkataramanan, Atilla Dogan. A Multi-UAV Simulation for Formation Reconfiguration[R]. AIAA2004-4800. Providence, Rhode Island: AIAA Modeling and Simulation Technologies Conference and Exhibit,2003

[4] Donald W.Manned/unmanned common architecture program (MCAP):a review[C]// Proceedings of the22nd Digital Avionics Systems Conference.2003: 6.B.4/1.6.B.4/7. 
[5] M.Valenti, T.Schouwenaars, Y.Kuwata, E.Feron and J. How Implementation of a Manned Vehicle-UAV Mission System[C].AAIA Guidance, Navigation and control Conference, Providence, RI, August 2004,AIAA2004

[6] Sarit Kraus. Negotiation and cooperation in mulfi-ageat environments. Artificial Intelligence.1997:79-97

[7] M.Ben-Bassat. Knowledge Requirement and Management in Expert Decision Support Systems for (Military) Situation Assessment [J]. IEEE Trans. on SMC.1982,12(4):479-490

[8] Jerome Azarewicz, Glenn Fala. Template-based Multi-agent Plan Recognition for Tactical Situation Assessment [A]. In: Proceedings of 5th conference on Artificial Intelligence Applications[C], March 1989:247-254

[9] G.Peterson, L.Axelsson, T.Jensen, etal. Multi-source Integration and Temporal Situation Assessment in Air Combat [J]. Proceedings of Information Decision and Control.1999:371-375

[10]Ge S S, Cui Y J. Dynamic motion planning for mobile robots using potential field method[J].Autonomous Robots,2002,13:207-222

[11] Kowalczyk W, Kozlowski K. Artificial potential based control for a large scale formation of mobile robots[C].Poland:4th International workshop on Robot Motion and Control,2004 